\title{
Hydrogen sulfide, a gaseous signaling molecule, elongates primary cilia on kidney tubular epithelial cells by activating extracellular signal-regulated kinase
}

\author{
Sang Jun Han ${ }^{1}$, Jee In Kim², Joshua H. Lipschutz", ${ }^{3,4}$, and Kwon Moo Park ${ }^{5, *}$ \\ ${ }^{1}$ Department of Biotechnology, College of Fisheries Sciences, Pukyong National University, Busan 48513, ${ }^{2}$ Department of Molecular Medicine, Keimyung \\ University School of Medicine, Daegu 42601, Korea, ${ }^{3}$ Department of Medicine, Medical University of South Carolina, ${ }^{4}$ Department of Medicine, Ralph H. \\ Johnson Veterans Affairs Medical Center, Charleston, SC 29425, USA, Department of Anatomy, BK21 Plus, Cardiovascular Research Institute, School of \\ Medicine, Kyungpook National University, Daegu 41944, Korea
}

\section{ARTICLE INFO}

Received July 20, 2021

Revised September 28, 2021

Accepted September 28, 2021

*Correspondence

Kwon Moo Park

E-mail: kmpark@knu.ac.kr

\section{Key Words}

Ciliogenesis

ERK

EXOC5

Hydrogen sulfide

Primary cilia

Sec10

\begin{abstract}
Primary cilia on kidney tubular cells play crucial roles in maintaining structure and physiological function. Emerging evidence indicates that the absence of primary cilia, and their length, are associated with kidney diseases. The length of primary cilia in kidney tubular epithelial cells depends, at least in part, on oxidative stress and extracellular signal-regulated kinase 1/2 (ERK) activation. Hydrogen sulfide $\left(\mathrm{H}_{2} \mathrm{~S}\right)$ is involved in antioxidant systems and the ERK signaling pathway. Therefore, in this study, we investigated the role of $\mathrm{H}_{2} \mathrm{~S}$ in primary cilia elongation and the downstream pathway. In cultured Madin-Darby Canine Kidney cells, the length of primary cilia gradually increased up to 4 days after the cells were grown to confluent monolayers. In addition, the expression of $\mathrm{H}_{2} \mathrm{~S}$-producing enzyme increased concomitantly with primary cilia length. Treatment with $\mathrm{NaHS}$, an exogenous $\mathrm{H}_{2} \mathrm{~S}$ donor, accelerated the elongation of primary cilia whereas DL-propargylglycine (a cystathionine $\gamma$-lyase inhibitor) and hydroxylamine (a cystathionine- $\beta$-synthase inhibitor) delayed their elongation. NaHS treatment increased ERK activation and Sec10 and Arl13b protein expression, both of which are involved in cilia formation and elongation. Treatment with U0126, an ERK inhibitor, delayed elongation of primary cilia and blocked the effect of NaHS-mediated primary cilia elongation and Sec10 and Arl13b upregulation. Finally, we also found that $\mathrm{H}_{2} \mathrm{~S}$ accelerated primary cilia elongation after ischemic kidney injury. These results indicate that $\mathrm{H}_{2} \mathrm{~S}$ lengthens primary cilia through ERK activation and a consequent increase in Sec10 and Arl13b expression, suggesting that $\mathrm{H}_{2} \mathrm{~S}$ and its downstream targets could be novel molecular targets for regulating primary cilia.
\end{abstract}

\section{INTRODUCTION}

Primary cilia are present in most mammalian cells and function as sensory organelles that transmit extracellular signals into cells [1]. In the kidney, a single primary cilium is located on the apical surface of all renal tubular epithelial cells, with the exception of collecting duct intercalated cells $[2,3]$. The primary cilium acts as a mechanosensor to detect fluid flow and composition of the ultrafiltrate, and maintain normal nephron structure $[4,5]$. Recent emerging evidence has demonstrated that changes in primary cilia are associated with various genetic and non-genetic diseases, such as autosomal dominant polycystic kidney disease, obesity, hypertension, and diabetes [6]. Moreover, recent reports revealed that the length of primary cilia reflects pathophysiologi- (i) (5) This is an Open Access article distributed under the terms of the Creative Commons Attribution Non-Commercial License, which permits unrestricted non-commercial use, distribution, and reproduction in any medium, provided the original work is properly cited. Copyright $\odot$ Korean J Physiol Pharmacol, pISSN 1226-4512, elSSN 2093-3827
Author contributions: S.J.H. and K.M.P. conceived and designed research. S.J.H. performed experiments. S.J.H., J.I.K., and K.M.P. analyzed data. S.J.H., J.I.K., J.H.L., and K.M.P. interpreted results of experiments. S.J.H. and K.M.P. prepared figures. S.J.H. and K.M.P. drafted manuscript. S.J.H., J.I.K., J.H.L., and K.M.P. edited and revised manuscript. S.J.H., J.I.K., J.H.L., and K.M.P. approved final version of manuscript. 
cal changes in the kidney [7].

In the kidney, we and others have found that the length of primary cilia is altered dynamically following ischemia and reperfusion (I/R) injury $[7,8]$. On severely damaged, dedifferentiating, and proliferating kidney tubule cells, primary cilia are shorter than normal length, or even absent, while they exceed the normal length in redifferentiating cells. Kidney tubular cells recovering from ischemic acute kidney injury have longer primary cilia compared to normal tubular cells, while tubular cells that successfully recover from ischemic injury have primary cilia with a normal length [7]. In addition, we also demonstrated that the elongation of primary cilia is at least partly regulated by the activation of extracellular signal-regulated kinase 1/2 (ERK) and the exocyst trafficking complex, of which Sec10 (also known as Exoc5) is a central component $[7,9,10]$.

Hydrogen sulfide $\left(\mathrm{H}_{2} \mathrm{~S}\right)$ is synthesized by two pyridoxal-5'phosphate-dependent enzymes, cystathionine $\beta$-synthase (CBS) and cystathionine $\gamma$-lyase (CSE), and a pyridoxal-5'-phosphateindependent enzyme, 3-mercaptpyruvate sulfurtransferase, through the transsulfuration pathway found in most mammalian tissues, including the kidney [11-14]. $\mathrm{H}_{2} \mathrm{~S}$ is currently recognized as a third endogenous gaseous physiological molecule and plays important pathophysiological roles in various organs, including the kidney [13-15]. Recent studies have demonstrated that $\mathrm{H}_{2} \mathrm{~S}$ acts as a signaling molecule that regulates intracellular signaling through mitogen-activating protein kinases, including ERK $[16,17]$. We reported previously that $\mathrm{H}_{2} \mathrm{~S}$ accelerates kidney recovery from I/R injury along with reduced renal fibrosis [18], and exogenous $\mathrm{H}_{2} \mathrm{~S}$ administration delays progression of kidney fibrosis after ureteral obstruction, while deleting the gene coding CSE exacerbates kidney fibrosis following ureteral obstruction in mice $[18,19]$. In addition, we found that inactivation of ERK aggravated tubular recovery after renal I/R injury and blocked the elongation of primary cilia induced by $\mathrm{I} / \mathrm{R}$ injury during the recovery period [9]; however, the role of $\mathrm{H}_{2} \mathrm{~S}$ in regulating the length of primary cilia, and the underlying mechanism(s), remain to be defined.

Therefore, in the present study, we investigated whether and how $\mathrm{H}_{2} \mathrm{~S}$ affects primary cilia length. Here, we report that $\mathrm{H}_{2} \mathrm{~S}$ elongates primary cilia by activating ERK with concomitant upregulations of Sec10 and Arl13b, suggesting that $\mathrm{H}_{2} \mathrm{~S}$ and its downstream targets could be molecular targets for regulating primary cilia length.

\section{METHODS}

\section{Cell culture}

Madin-Darby Canine Kidney (MDCK) cells were cultured in MEM with 5\% FBS and penicillin/streptomycin (penicillin, 100 $\mathrm{IU} / \mathrm{ml}$; streptomycin, $100 \mu \mathrm{g} / \mathrm{ml}$ ). For immunofluorescence stain- ing of primary cilia, cells were cultured on glass coverslips. When MDCK cells reached $100 \%$ confluence, cells were treated with 1, 10, and $50 \mu \mathrm{M}$ NaHS, $10 \mu \mathrm{M}$ U0126 (a MEK inhibitor; SigmaAldrich, St. Louis, MO, USA), 0.5 mM DL-Propargylglycine (PAG, a CSE inhibitor; Sigma-Aldrich), $0.1 \mathrm{mM}$ hydroxylamine (HA, a CBS inhibitor; Sigma-Aldrich) or vehicle (distilled water) as described in the figure legends. The chosen dosages of PAG and HA were based on previous studies [20]. Cells were harvested using cell lysis buffer or fixed with $4 \%$ paraformaldehyde and processed for Western blot analyses or immunofluorescence staining, respectively.

\section{Animal preparation}

Eight-week-old C57BL/6 male mice (Koatech, Pyeongtaek, Korea) were used in experiments. All animal experiments were carried out in accordance with the Animal Care and Use Committees of Kyungpook National University and Pukyong National University's guide lines. For the induction of ischemia, kidneys were exposed through flank incisions, and the renal pedicles were clamped completely for $30 \mathrm{~min}$ using microaneurysm clamps while the mice were anesthetized with pentobarbital sodium (50 $\mathrm{mg} / \mathrm{kg}$ body weight [BW] or to effect). The sham operation followed the identical method of ischemia surgery, with the exception of the clamping of the renal pedicle. Mice received daily intraperitoneal administration of NaHS $(500 \mu \mathrm{g} / \mathrm{kg} \mathrm{BW})$, PAG (50 $\mathrm{mg} / \mathrm{kg} \mathrm{BW)} \mathrm{or} 0.9 \% \mathrm{NaCl}$ (vehicle), beginning 2 days after ischemia until the end of the experiment. Chosen NaHS and PAG dosages were based on our and other previous studies [18,21-23]. NaHS and PAG were prepared freshly before intraperitoneal injection. Eight days after ischemia, kidney sections were subjected to immunofluorescent staining using anti-acetylated $\alpha$-tubulin (Sigma-Aldrich) and aquaporin 1 (Alomone Labs, Jerusalem, Israel) antibodies. Pictures were obtained from the outer medulla.

\section{Measurement of primary cilium length}

Fixed kidneys or cells were processed for immunofluorescence microscopy by staining with anti-acetylated $\alpha$-tubulin (SigmaAldrich) antibody. Images were captured using Axioplan-2 epifluorescence microscope (Carl Zeiss, Oberkochen, Germany). For measurement of primary cilia length, more than 50 cells from each experiment were used. iSolution (IMT i-Solution, Rochester, NY, USA) software was used to trace and measure the length of primary cilia in the captured images. The length of the curved primary cilia was calculated by summing the straight parts of curved primary cilia. All measured primary cilia were used to analyze the percentage of primary cilia in each length range.

\section{Western blot analysis}

Western blot analyses were performed as described previously 
[24]. Briefly, Cell lysates were separated on 10\% SDS-PAGE gels and then transferred to Immobilon membranes (Millipore Corp., Bedford, MA, USA). The membranes were incubated with antibodies against phospho-ERK (Cell Signal Technology, Beverely, MA, USA), -total ERK (Santa Cruz Biotechnology Inc., Santa Cruz, CA, USA), Sec10 [10], CBS (Santa Cruz Biotechnology Inc.), Arl13b (Proteintech, Chicago, IL, USA) and GAPDH (Novus Biologicals, Littleton, CO, USA). After washing, the membranes were incubated with horse radish peroxidase-conjugated secondary antibodies against the appropriate primary antibodies, exposed to Western Lighting Chemiluminescence Reagent (NEL101; PerkinElmer LAS, Boston, MA, USA), and then developed using X-ray film.

\section{Statistical analysis}

Statistical differences between the groups were evaluated with an analysis of variance using a two-tailed Student's t-test and oneway ANOVA plus Tukey's post hoc multiple comparison test. For analysis of the ratio of primary cilia to proximal tubular nuclei, logistic regression was used. Results were expressed as mean \pm SEM. A p-value of $<0.05$ was regarded as significant difference.

\section{RESULTS}

\section{Primary cilium length correlates with the expression of $\mathrm{H}_{2} \mathrm{~S}$-producing enzyme}

To investigate the correlation between the length of primary cilia and the expression of $\mathrm{H}_{2} \mathrm{~S}$-producing enzyme, we measured primary cilia length, and the expression of CBS in renal tubule epithelial cells. Primary cilia length gradually increased up to 4 days after MDCK cells were grown to confluent monolayers (Fig. $1 \mathrm{~A}, \mathrm{~B})$. The expression levels of CBS showed a similar gradual increase (Fig. 1C). These data suggest that an increase of the $\mathrm{H}_{2} \mathrm{~S}$ producing enzyme may be associated with elongation of primary cilia.

A
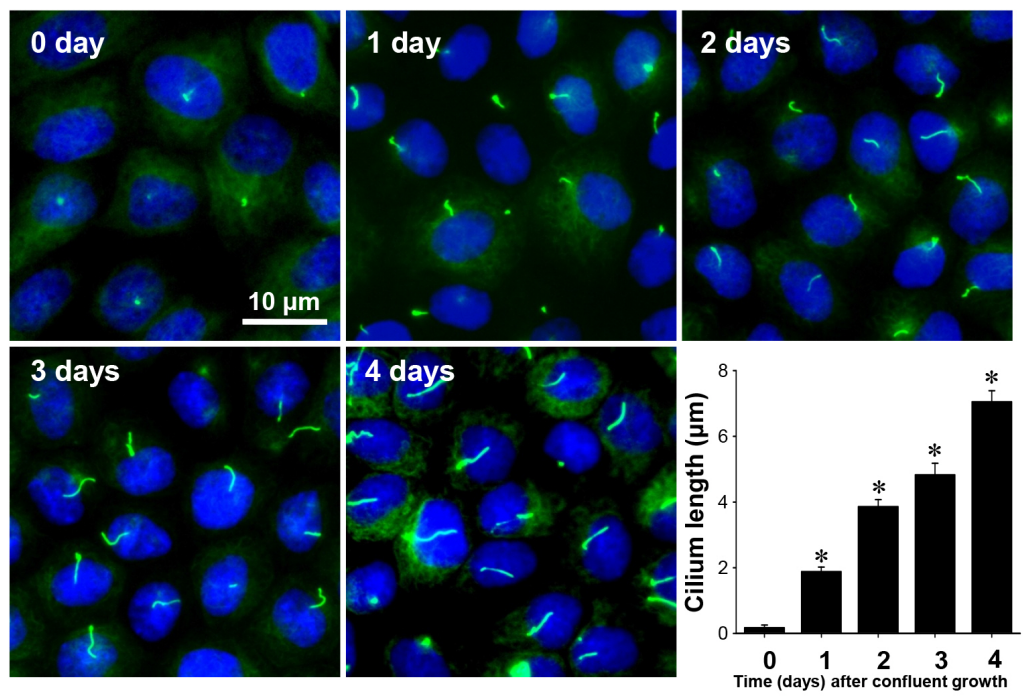

B

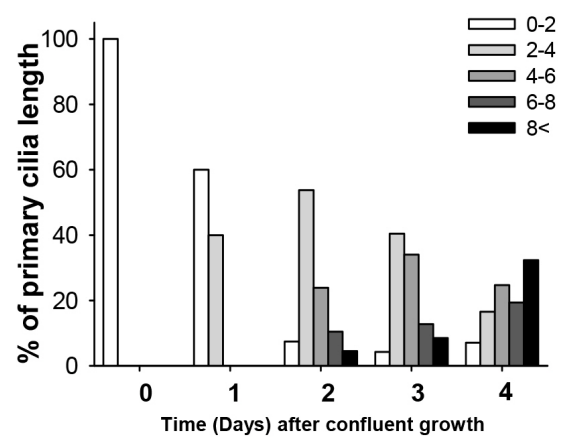

C
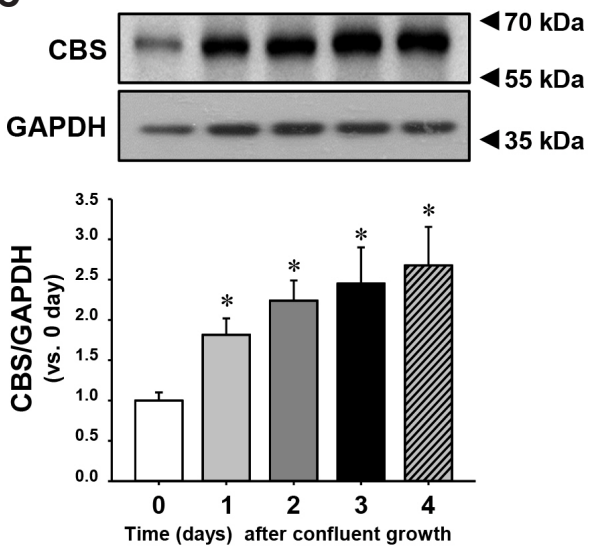

Fig. 1. Relationship between expression of $\mathrm{H}_{2} \mathrm{~S}$-producing enzyme and primary cilium length in MDCK cells. MDCK cells grown on the coverslip were fixed and processed for immunofluorescence staining using anti-acetylated- $\alpha$ tubulin antibody (green) at the indicated day following growth of the cells to confluent monolayers. DAPI (blue) indicates nuclear staining. (A) Representative images and length of primary cilia are shown at the indicated times. (B) The percentage of primary cilia in each length range are shown at the indicated times. (C) Representative immunoblot image of CBS. GAPDH was used as loading control. The results are expressed as the mean \pm SEM $(n=3-4)$. $\mathrm{H}_{2} \mathrm{~S}$, hydrogen sulfide; MDCK, Madin-Darby Canine Kidney; CBS, cystathionine $\beta$-synthase. ${ }^{*} p<0.05$ vs. 0 day. 


\section{$\mathrm{H}_{2} \mathrm{~S}$ elongates primary cilia in cultured tubule cells}

Next, we assessed whether $\mathrm{H}_{2} \mathrm{~S}$ elongated primary cilia on MDCK cells. MDCK cells were treated with NaHS (an exogenous $\mathrm{H}_{2} \mathrm{~S}$ donor), $\mathrm{PAG}$ (an inhibitor of CSE), HA (an inhibitor of CBS), and the combination of PAG and HA daily for 4 days after cells reached confluence. Treatment with NaHS elongated primary cilia compared with those of vehicle-treated cells. In contrast, treatment with either PAG or HA shortened the length of primary cilia, and combined treatment with both inhibitors prevented the elongation of primary cilia to a greater extent than either alone, and the ratio of the short primary cilia $(0-2 \mu \mathrm{m})$ were slightly increased by the combined treatment with both inhibitors (Fig. 2A, $\mathrm{B}$. These results suggest that both endogenous and exogenous $\mathrm{H}_{2} \mathrm{~S}$ can elongate the primary cilia in MDCK cells.

\section{$\mathrm{H}_{2} \mathrm{~S}$ elongates primary cilia in MDCK cells via ERK activation}

We reported previously that ERK and Sec10 induced ciliogenesis and elongation of primary cilia in kidney tubule cells [9] and ADP-ribosylation factor-like protein 13B (Arl13b) which is essential for ciliogenesis by interacting with Sec10 $[25,26]$. Here, we investigated whether $\mathrm{H}_{2} \mathrm{~S}$ regulates ERK activation and Sec10 and Arl13b expression. Treatment of MDCK cells with $10 \mu \mathrm{M}$ NaHS activated ERK to a greater extent than other concentrations of NaHS (Fig. 3A, B). Treatment with 10 or $50 \mu \mathrm{M}$ NaHS increased
Sec10 and Arl13b expressions to a similar extent (Fig. 3A, C, D). Treatment with 10 or $50 \mu \mathrm{M}$ NaHS increased the length of primary cilia to a similar length. However, $1 \mu \mathrm{M}$ NaHS didn't affect the length of primary cilia (Fig. 3E, F). Next, we assessed whether NaHS treatment elongated primary cilia via ERK activation. MDCK cells were treated with NaHS or vehicle along with U0126, a MEK and, therefore, ERK inhibitor. Treatment with NaHS activated ERK and this effect was completely abolished by treatment with U0126 (Fig. 4A, C). In addition, treatment with NaHS increased Sec10 and Arl13b expressions, and these increases were blocked by U0126 (Fig. 4B, D, E). Consistent with ERK activation and Sec10 and Arl13b expression, NaHS accelerated elongation of primary cilia, and treatment with U0126 suppressed this elongation. Interestingly, the shortening of primary cilia by U0126 could not be reversed by treatment with NaHS (Fig. 4F-H). However, U0126 treatment alone didn't affect Sec10 and Arl13b expression, indicating ERK activation is specifically necessary for NaHSmediated elongation of primary cilia.

\section{Hydrogen sulfide elongates primary cilia length on kidney tubule cells after ischemia/reperfusion injury}

In our previous study, we have found that kidney cells recovering from $\mathrm{I} / \mathrm{R}$ injury have longer primary cilia, and the elongation of primary cilia is associated with repairs of polarity and differentiation of injured tubule cells $[27,28]$ and we also demonstrated that NaHS treament accelerated recovery form kidney ischemic

A
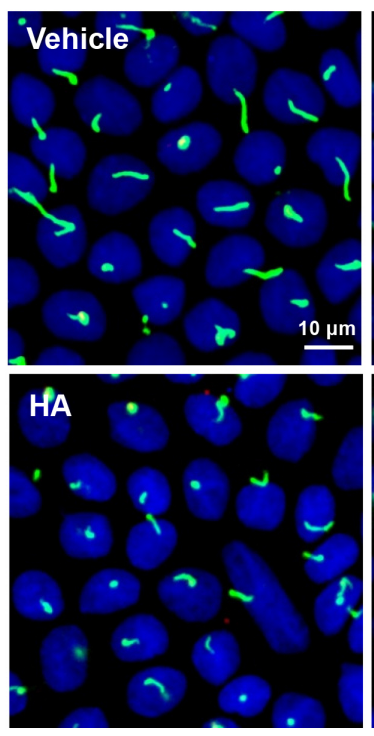
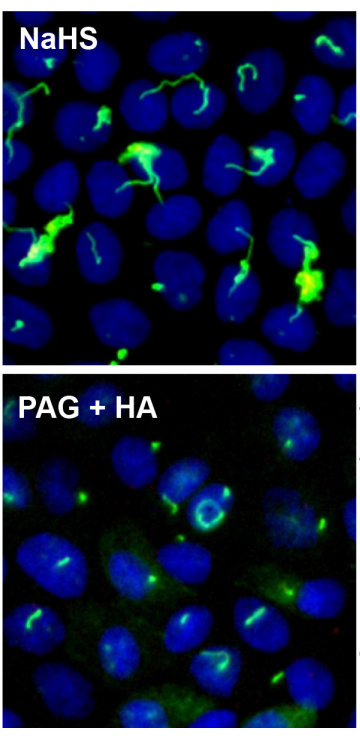
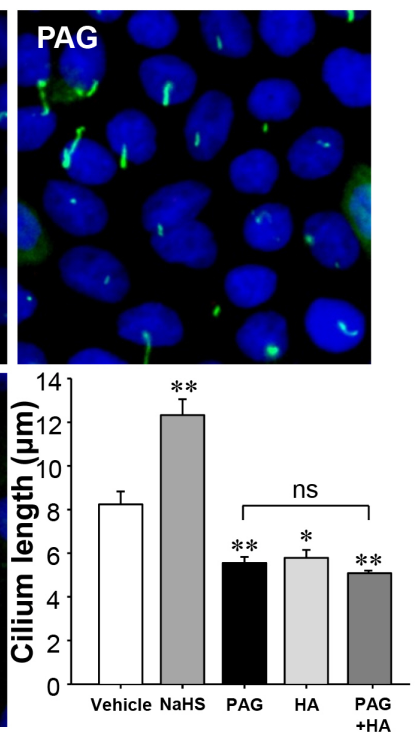

B

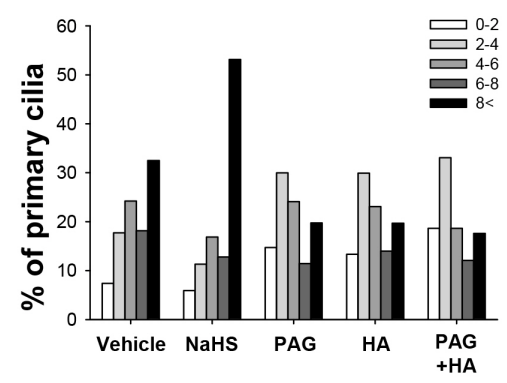

Fig. 2. Hydrogen sulfide elongates primary cilia in cultured MDCK cells. MDCK cells grown on coverslips were treated with vehicle, $10 \mu \mathrm{M}$ NaHS, $0.5 \mathrm{mM}$ PAG, $0.1 \mathrm{mM} \mathrm{HA}$ or combination of PAG and HA daily after cells were grown to confluency. After 4 days, cells were fixed and processed for immunofluorescence staining using anti-acetylated-tubulin antibody (green). DAPI (blue) indicates nuclear staining. (A) Representative images of primary cilia and the length of primary cilia are shown. (B) The percentage of primary cilia in each length range is shown. The results are expressed as the mean \pm SEM $(n=4)$. MDCK, Madin-Darby Canine Kidney; HA, hydroxylamine; PAG, propargylglycine; $n$, non-significant. ${ }^{*} p<0.05$ vs. vehicle. ${ }^{* *} p<0.01$ vs. vehicle. 


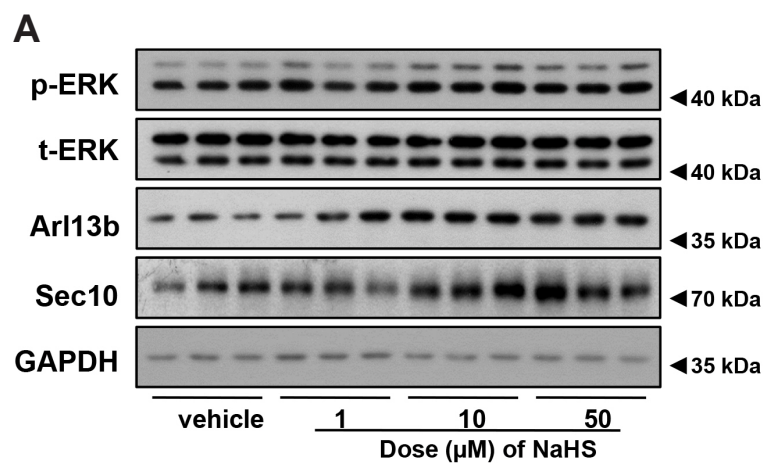

B

E
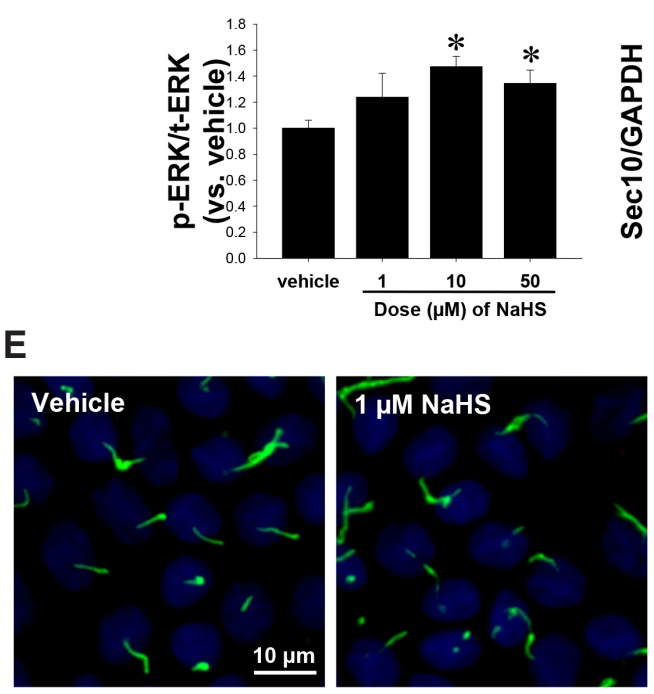

C

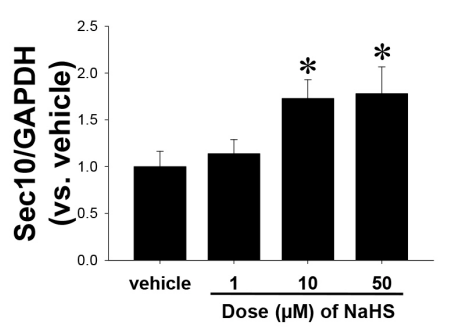

D
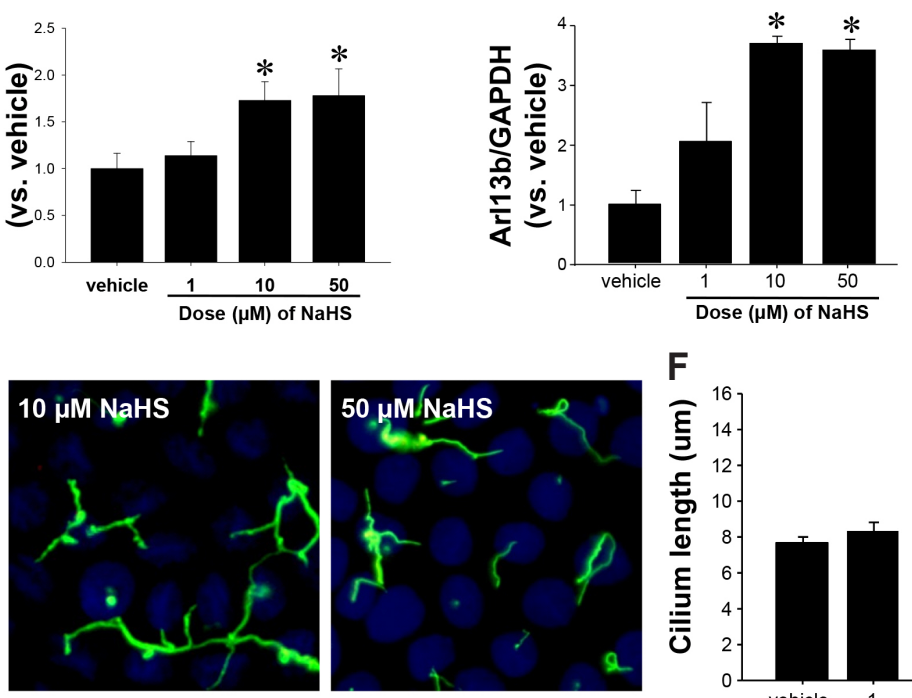

Fig. 3. Hydrogen sulfide increases expressions of phospho-ERK and Sec10. MDCK cells were treated with vehicle or 1, 10, and $50 \mu \mathrm{M}$ of NaHS after cells reached confluence. (A) Ten minutes after treatment, cell lysates were subjected to Western blot analysis using antibodies against Sec10, Arl13b, phosphorylated ERK (p-ERK), and total-ERK (t-ERK). GAPDH was used as loading control. (B-D) Band densities were measured using ImageJ software. (E, F) After 4 days, cells were fixed and processed for immunofluorescence staining using anti-acetylated-tubulin antibody (green). DAPI (blue) indicates nuclear staining. The results are expressed as the mean \pm SEM $(n=4)$. ERK, extracellular signal-regulated kinase. ${ }^{*} p<0.05$ vs. vehicle.

injury while PAG treatment delayed that by regulating antioxidant system and ERK activation. However, it is unclear whether $\mathrm{H}_{2} \mathrm{~S}$ regulates the length of primary cilia after $\mathrm{I} / \mathrm{R}$ and that the length change is related to kidney recovery from $I / R$ injury. I/R insult elongated primary cilia on kidney tubule cells 8 days after $\mathrm{I} / \mathrm{R}$, and NaHS treatment accelerated the elongation of primary cilia and increased the ratio of primary cilia to proximal tubular cell nuclei, whereas PAG treatment delayed those elongation and decreased the ratio of nuclei (Fig. 5A-D). These results suggest that $\mathrm{H}_{2} \mathrm{~S}$ elongates primary cilia length and the elongation of primary cilia is associated with the kidney repair process following I/R injury.

\section{DISCUSSION}

In the present study, we demonstrated, for the first time, that
$\mathrm{H}_{2} \mathrm{~S}$ elongates primary cilia via increased ERK activation and Sec10 and Arl13b expression in cultured kidney tubule cells (Fig. 6). These findings suggest that $\mathrm{H}_{2} \mathrm{~S}$ and its production system play important roles in regulating primary cilia length, and thus help to maintain primary cilia homeostasis as well as normal kidney tubule cell architecture and function.

In previous studies, we, and others, found that the lengthening of primary cilia in kidney tubule cells is important for epithelial differentiation, maintaining the epithelial phenotype, and enhancing compensatory adaptation after injury $[27,28]$. During the initial and extended phases of ischemic kidney injury, primary cilia are short, or even absent, and primary cilia start to elongate as renal tubule cells undergo dedifferentiation and proliferation in the maintenance phase. Subsequently, primary cilia are elongated on redifferentiated and repolarized cells during the repair phase. Although the detailed mechanisms have not been elucidated yet, we speculate that we speculate that for primary cilia to return to 


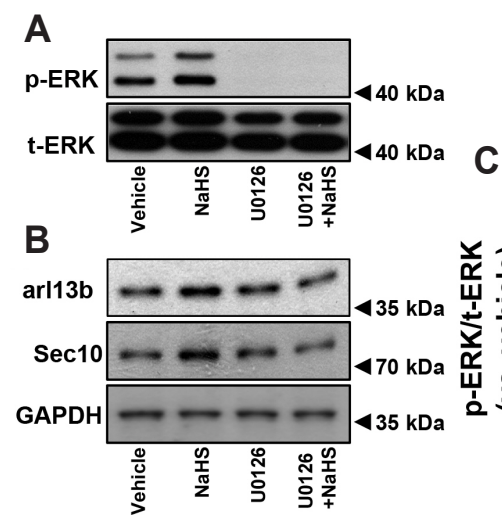

$\mathrm{F}$
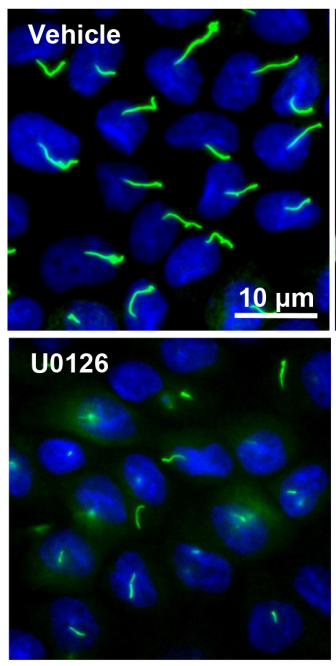
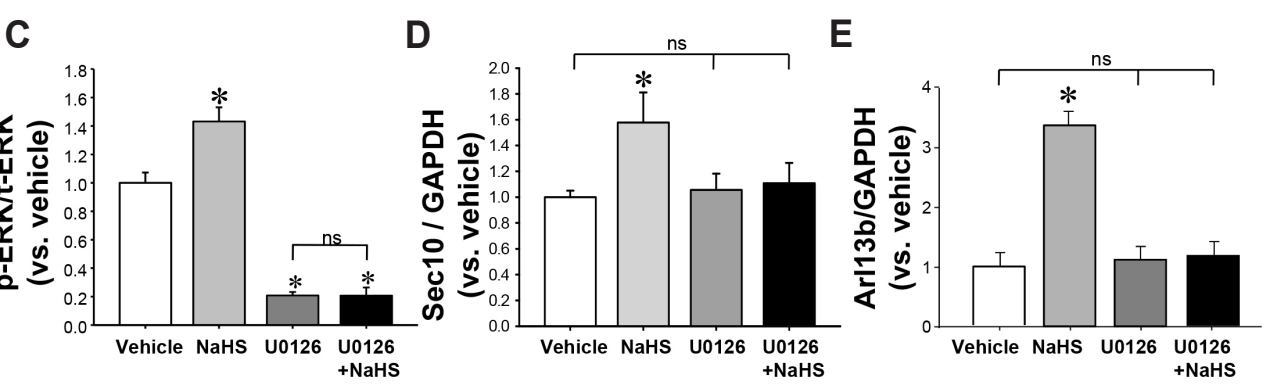

\section{G}
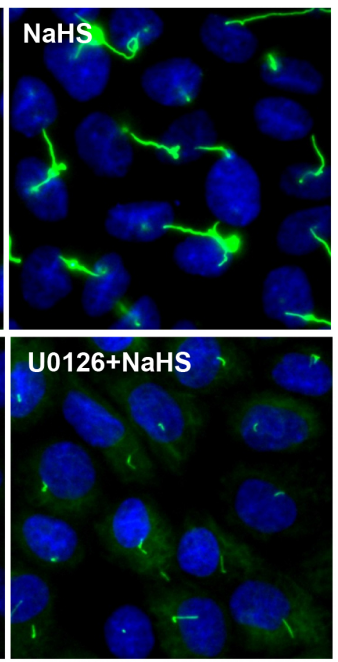

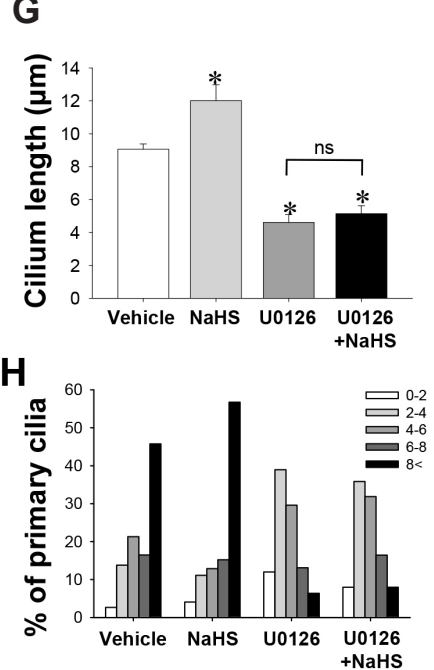

Fig. 4. Inhibition of ERK activation prevents hydrogen sulfide-induced elongation of primary cilia. MDCK cells were treated daily with either vehicle or $10 \mu \mathrm{M}$ NaHS 30 min after treatment with either vehicle (DMSO) or $10 \mu \mathrm{M}$ U0126. Cell lysates were subjected to Western blot analysis, which was performed for phospho-ERK ( $p$-ERK, A), total-ERK (t-ERK, A), Arl13b and Sec10 (B) 10 min after treatment. (C-E) Band densities were measured using ImageJ software. (F) Four days after treatment, cells were fixed and processed for immunofluorescence staining using anti-acetylated- $\alpha$-tubulin antibody (green). DAPI (blue) indicates nuclear staining. The length of primary cilia $(\mathrm{G})$ and the percentage of primary cilia in each length range (H) were measured. The results are expressed as the mean \pm SEM $(n=4)$. ERK, extracellular signal-regulated kinase; MDCK, Madin-Darby Canine Kidney; ns, non-significant. ${ }^{*} p<0.05$ vs. vehicle.

normal length, they may need to first elongated, and then return to normal length by reabsorption rather than directly proceeding to normal length as suggested by others $[29,30]$. So, it is possible that hydrogen sulfide could accelerate the return of primary cilia to normal length (16 days after reperfusion) by elongating primary cilia in the maintenance phase (8 days after reperfusion).

In a recent study, we also demonstrated that inhibition of primary cilia by knocking down the ciliary protein genes $A r l 13 b$ and Ift20 accelerated TGF- $\beta$-induced epithelial-mesenchymal transition, one of the major mechanisms for the development of renal fibrosis [31]. There are several factors that can regulate primary cilia length, including: cyclic AMP, PKA activity, and intracellular $\mathrm{Ca}^{2+}$ levels. In previous studies, we demonstrated that the elongation of primary cilia is regulated by reactive oxygen species and ERK activation [7,9]. Treatment with Mn(III) tetrakis(1-methyl4-pyridyl) porphyrin (MnTMPyP), an antioxidant, during the repair phase of I/R injury accelerated normalization of primary cilia length concomitant with a decrease in oxidative stress in the kidney [7]. In MDCK cells, treatment with $\mathrm{H}_{2} \mathrm{O}_{2}$, a reactive oxygen species, shortened primary cilia by releasing ciliary fragments into the medium, and MnTMPyP inhibited this deciliation [32]. In our recent study, we found that renal I/R injury significantly decreased $\mathrm{H}_{2} \mathrm{~S}$ levels and reduced both enzyme activity and expression of $\mathrm{H}_{2} \mathrm{~S}$ producing enzymes and treatment with NaHS accelerated recovery of kidney histological and functional changes after renal I/R injury [18]. In the present study, we found that the expression of CBS was increased with elongation of primary cilia, and treatment with NaHS accelerated elongation of primary cilia, while treatment with inhibitors of $\mathrm{H}_{2} \mathrm{~S}$ producing-enzymes suppressed elongation of primary cilia after renal I/R injury (Fig. 5). However, we couldn't find any change in primary cilia length in kidneys subjected to sham surgery after NaHS or PAG treatment. Although very powerful as translational studies, there are limitations with in vivo studies. With in vivo approaches, it is nearly 

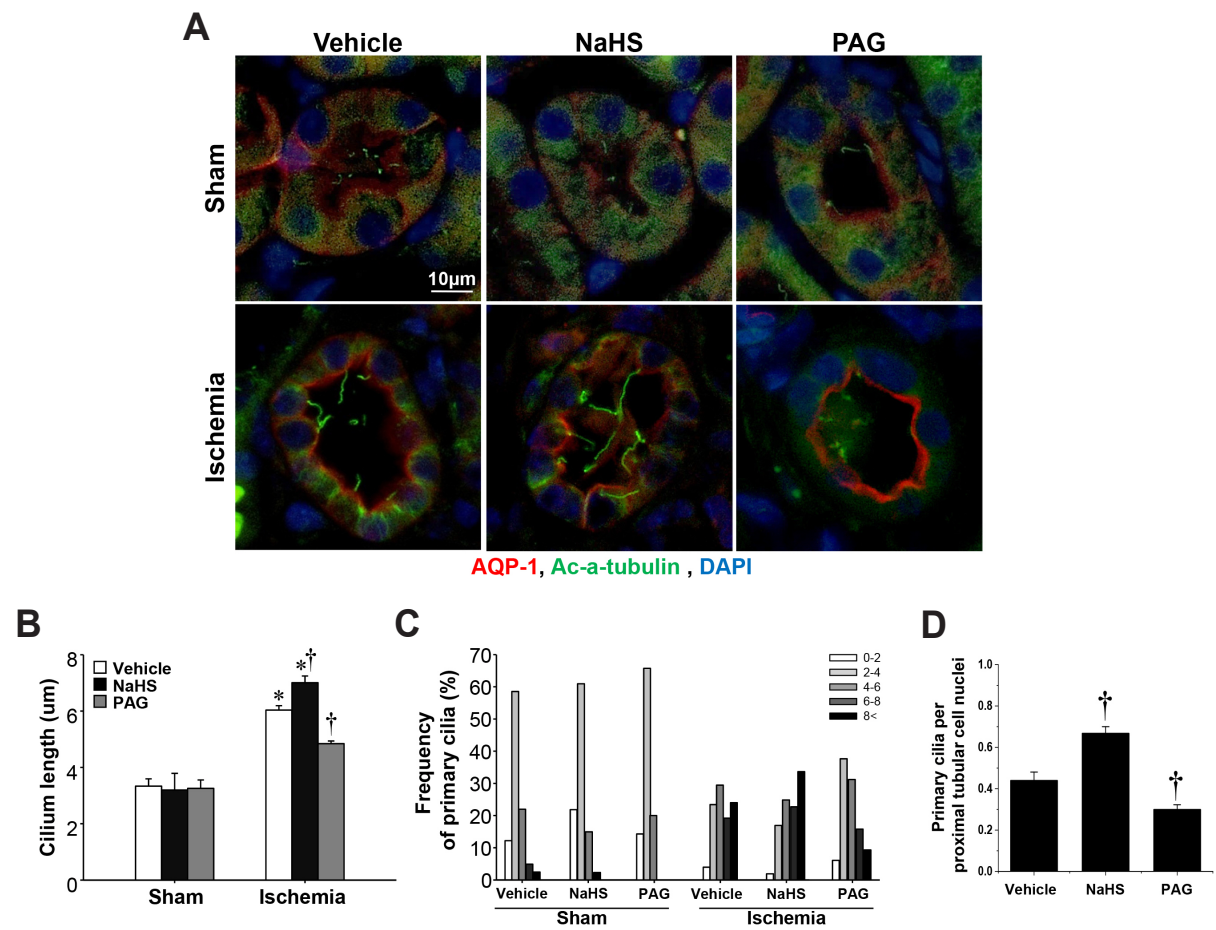

Fig. 5. Effect of $\mathrm{H}_{2} \mathrm{~S}$ on the primary cilia elongation and recovery of kidney after ischemia/reperfusion injury. Mice were subjected to either 30 min of bilateral renal ischemia or sham surgery. Mice were treated daily with NaHS ( $500 \mu \mathrm{g} / \mathrm{kg} \mathrm{BW})$, PAG ( $50 \mathrm{mg} / \mathrm{kg} \mathrm{BW}$ ) or vehicle (0.9\% saline) beginning 2 days after surgery. (A) Eight days after ischemia, kidney sections were subjected to immunofluorescent staining using anti-acetylated $\alpha$-tubulin (green) and aquaporin 1 (AQP-1, red) antibodies. Pictures were obtained from the outer medulla. Average length of primary cilia (B), frequency of primary cilia length $(C)$, and the ratio of primary cilia to proximal tubular cell nuclei $(D)$ were measured as described in the Methods. Results were expressed as the means $\pm \mathrm{SEM}(n=6)$. $\mathrm{H}_{2} \mathrm{~S}$, hydrogen sulfide; BW, body weight; $\mathrm{PAG}$, propargylglycine. ${ }^{*} \mathrm{p}<0.05$ vs. their respective vehicle-treated sham on the same day. ${ }^{\dagger} \mathrm{p}<0.05 \mathrm{vs}$. vehicle-treated ischemia on the same day.

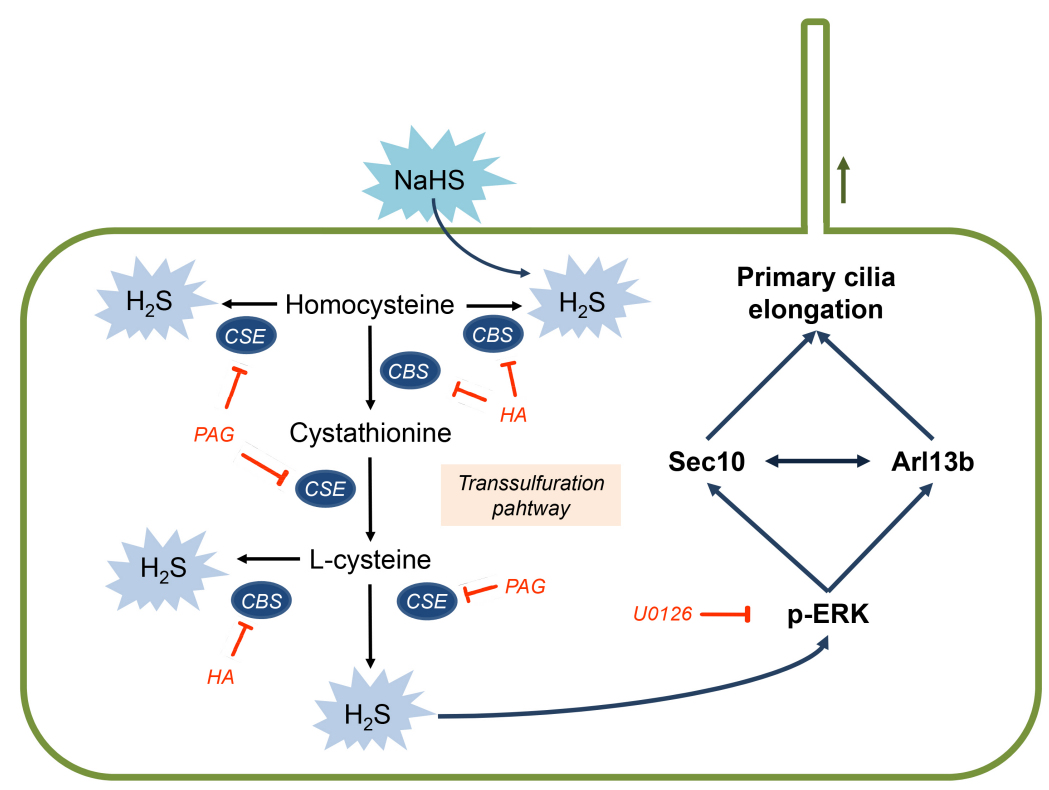

Fig. 6. Schematic of the proposed mechanisms for $\mathrm{H}_{2} \mathrm{~S}$-mediated primary cilia elongation. The biological production of $\mathrm{H}_{2} \mathrm{~S}$ in the kidney is mediated by the transsulfuration pathway. CSE and CBS generate $\mathrm{H}_{2} \mathrm{~S}$ by using L-cysteine and homocysteine as substrates. PAG and CBS are inhibitor of CSE and CBS respectively, and NaHS is the exogenous $\mathrm{H}_{2} \mathrm{~S}$ donor. $\mathrm{H}_{2} \mathrm{~S}$ elongates primary cilia by activating ERK with concomitant upregulation of Sec10 and Arl13b. $\mathrm{H}_{2} \mathrm{~S}$, hydrogen sulfide; CBS cystathionine $\beta$-synthase; CSE, cystathionine $\gamma$-lyase; $\mathrm{HA}$, hydroxylamine; PAG, propargylglycine. 
impossible to dissect the cause-and-effect relationship and it is hard to rule out other diverse compensatory effects. Moreover, there are multiple cell types and organ systems being affected by exogenous changes including renal tubular cells, endothelial cells, and leukocytes. In normal conditions, tissues and cells maintain homeostasis, but in pathological conditions such as ischemic injury, they lose the ability to maintain homeostasis. In this study, NaHS did not affect primary cilia length in sham kidneys. However, NaHS treatment elongated primary cilia during the recovery phase of ischemic kidney injury. We speculate that these discrepancies may be due to the inherent differences between physiological and pathological conditions.

Many different ciliary proteins are involved in regulating primary cilia. Sec10 is a central member of the exocyst trafficking complex which also includes Sec3, Sec5, Sec6, Sec8, Sec15, Exo70, and Exo84. Sec10-regulated trafficking is essential for establishing cell polarity [33]. In a previous study, we reported that Sec10 knockdown inhibited ciliogenesis and elongation of primary cilia in MDCK cells, whereas Sec10 over-expression increased ciliogenesis and cilia length. These results indicate that Sec10 is critical factor for ciliogenesis [10]. Finally, we showed that Sec10 overexpression protected MDCK cells from injury with $\mathrm{H}_{2} \mathrm{O}_{2}$ in a MAPK-dependent manner [34]. In the present study, NaHS increased Sec10 expression and accelerated the elongation of primary cilia, whereas PAG and HA suppressed these effects. Other studies have reported that $\mathrm{H}_{2} \mathrm{~S}$ activates ERK in human colon cancer cells [17], aorta smooth muscle cells [35], and neuronal stem cells [36]. We reported previously that inactivation of ERK suppressed elongation of primary cilia and restoration of cell polarity in kidney tubule cells after ischemic kidney injury [9] These findings indicate that ERK activation accelerates elongation of primary cilia in mouse kidney tubule cells. In the present study, we found that ERK inactivation shortened primary cilia in MDCK cells, and administration of NaHS induced ERK activation and primary cilia elongation and increased Sec10 significantly more than in the U0126-treated group. ERK phosphorylation is one of the earliest MAPKs induced after renal IR injury and drug treatment. ERK is phosphorylated within $10 \mathrm{~min}$ of reperfusion and drops to intermediate values between 2 and $4 \mathrm{~h}$ after reperfusion [37]. So, in the present study, 8 days after reperfusion would not be proper time point to analyze ERK phosphorylation induced by ischemic injury or NaHS administration.

In conclusion, our present results suggest that $\mathrm{H}_{2} \mathrm{~S}$ accelerates elongation of primary cilia by activating ERK and up-regulating Sec10 and Arl13b. This suggests that $\mathrm{H}_{2} \mathrm{~S}$ is a novel target for the regulation of primary cilia in kidney tubule cells, and a potential regulator for modulating changes in primary cilia-associated genetic and non-genetic kidney disease.

\section{ACKNOWLEDGEMENTS}

This work was supported by the Pukyong National University Research Fund in 2020 (CD20201553), the National Research Foundation Grant funded by the Korean Government (NRF2020R1A2C2006903 to Park, K.M, NRF-2017R1A2A2A05069707 to Park, K.M., and NRF-2021R1C1C1003333 to Han, S.J.), Dialysis Clinic, Inc to Lipschutz, J.H. and the United States Department of Veterans Affairs (Merit Award I01 BX000820 to Lipschutz, J.H.).

\section{CONFLICTS OF INTEREST}

The authors declare no conflicts of interest.

\section{REFERENCES}

1. Badano JL, Mitsuma N, Beales PL, Katsanis N. The ciliopathies: an emerging class of human genetic disorders. Annu Rev Genomics Hum Genet. 2006;7:125-148.

2. Bulger RE, Siegel FL, Pendergrass R. Scanning and transmission electron microscopy of the rat kidney. Am J Anat. 1974;139:483-501.

3. Webber WA, Lee J. Fine structure of mammalian renal cilia. Anat Rec. 1975;182:339-343.

4. Praetorius HA, Spring KR. The renal cell primary cilium functions as a flow sensor. Curr Opin Nephrol Hypertens. 2003;12:517-520.

5. Praetorius HA, Spring KR. Removal of the MDCK cell primary cilium abolishes flow sensing. J Membr Biol. 2003;191:69-76.

6. Zhang S, Pan C, Zhou F, Yuan Z, Wang H, Cui W, Zhang G. Hydrogen sulfide as a potential therapeutic target in fibrosis. Oxid Med Cell Longev. 2015;2015:593407.

7. Kim JI, Kim J, Jang HS, Noh MR, Lipschutz JH, Park KM. Reduction of oxidative stress during recovery accelerates normalization of primary cilia length that is altered after ischemic injury in murine kidneys. Am J Physiol Renal Physiol. 2013;304:F1283-F1294.

8. Wang S, Dong Z. Primary cilia and kidney injury: current research status and future perspectives. Am J Physiol Renal Physiol. 2013;305:F1085-F1098.

9. Jang HS, Han SJ, Kim JI, Lee S, Lipschutz JH, Park KM. Activation of ERK accelerates repair of renal tubular epithelial cells, whereas it inhibits progression of fibrosis following ischemia/reperfusion injury. Biochim Biophys Acta. 2013;1832:1998-2008.

10. Zuo X, Guo W, Lipschutz JH. The exocyst protein Sec10 is necessary for primary ciliogenesis and cystogenesis in vitro. Mol Biol Cell. 2009;20:2522-2529.

11. Fiorucci S, Distrutti E, Cirino G, Wallace JL. The emerging roles of hydrogen sulfide in the gastrointestinal tract and liver. Gastroenterology. 2006;131:259-271.

12. Kimura H. Hydrogen sulfide: its production, release and functions. Amino Acids. 2011;41:113-121.

13. Szabó C. Hydrogen sulphide and its therapeutic potential. Nat Rev Drug Discov. 2007;6:917-935.

14. Wang R. Two's company, three's a crowd: $c a n \mathrm{H}_{2} \mathrm{~S}$ be the third endogenous gaseous transmitter? FASEB J. 2002;16:1792-1798.

15. Banerjee R. Hydrogen sulfide: redox metabolism and signaling. An- 
tioxid Redox Signal. 2011;15:339-341.

16. Zhi L, Ang AD, Zhang H, Moore PK, Bhatia M. Hydrogen sulfide induces the synthesis of proinflammatory cytokines in human monocyte cell line U937 via the ERK-NF-kappaB pathway. J Leukoc Biol. 2007;81:1322-1332.

17. Cai WJ, Wang MJ, Ju LH, Wang C, Zhu YC. Hydrogen sulfide induces human colon cancer cell proliferation: role of Akt, ERK and p21. Cell Biol Int. 2010;34:565-572.

18. Han SJ, Kim JI, Park JW, Park KM. Hydrogen sulfide accelerates the recovery of kidney tubules after renal ischemia/reperfusion injury. Nephrol Dial Transplant. 2015;30:1497-1506.

19. Han SJ, Noh MR, Jung JM, Ishii I, Yoo J, Kim JI, Park KM. Hydrogen sulfide-producing cystathionine $\gamma$-lyase is critical in the progression of kidney fibrosis. Free Radic Biol Med. 2017;112:423-432.

20. Asimakopoulou A, Panopoulos P, Chasapis CT, Coletta C, Zhou Z, Cirino G, Giannis A, Szabo C, Spyroulias GA, Papapetropoulos A. Selectivity of commonly used pharmacological inhibitors for cystathionine $\beta$ synthase (CBS) and cystathionine $\gamma$ lyase (CSE). Br J Pharmacol. 2013;169:922-932.

21. Jung KJ, Jang HS, Kim JI, Han SJ, Park JW, Park KM. Involvement of hydrogen sulfide and homocysteine transsulfuration pathway in the progression of kidney fibrosis after ureteral obstruction. Biochim Biophys Acta. 2013;1832:1989-1997.

22. Fan HN, Wang HJ, Yang-Dan CR, Ren L, Wang C, Li YF, Deng Y. Protective effects of hydrogen sulfide on oxidative stress and fibrosis in hepatic stellate cells. Mol Med Rep. 2013;7:247-253.

23. Zhu YZ, Wang ZJ, Ho P, Loke YY, Zhu YC, Huang SH, Tan CS, Whiteman M, Lu J, Moore PK. Hydrogen sulfide and its possible roles in myocardial ischemia in experimental rats. J Appl Physiol (1985). 2007;102:261-268.

24. Han SJ, Jang HS, Noh MR, Kim J, Kong MJ, Kim JI, Park JW, Park $\mathrm{KM}$. Mitochondrial $\mathrm{NADP}^{+}$-dependent isocitrate dehydrogenase deficiency exacerbates mitochondrial and cell damage after kidney ischemia-reperfusion injury. J Am Soc Nephrol. 2017;28:1200-1215.

25. Larkins CE, Aviles GD, East MP, Kahn RA, Caspary T. Arl13b regulates ciliogenesis and the dynamic localization of Shh signaling proteins. Mol Biol Cell. 2011;22:4694-4703.

26. Seixas C, Choi SY, Polgar N, Umberger NL, East MP, Zuo X, Moreiras H, Ghossoub R, Benmerah A, Kahn RA, Fogelgren B,
Caspary T, Lipschutz JH, Barral DC. Arl13b and the exocyst interact synergistically in ciliogenesis. Mol Biol Cell. 2016;27:308-320.

27. Verghese E, Ricardo SD, Weidenfeld R, Zhuang J, Hill PA, Langham $\mathrm{RG}$, Deane JA. Renal primary cilia lengthen after acute tubular necrosis. J Am Soc Nephrol. 2009;20:2147-2153.

28. Wang L, Weidenfeld R, Verghese E, Ricardo SD, Deane JA. Alterations in renal cilium length during transient complete ureteral obstruction in the mouse. J Anat. 2008;213:79-85.

29. Keeling J, Tsiokas L, Maskey D. Cellular mechanisms of ciliary length control. Cells. 2016;5:6.

30. Avasthi P, Marshall WF. Stages of ciliogenesis and regulation of ciliary length. Differentiation. 2012;83:S30-S42.

31. Han SJ, Jung JK, Im SS, Lee SR, Jang BC, Park KM, Kim JI. Deficiency of primary cilia in kidney epithelial cells induces epithelial to mesenchymal transition. Biochem Biophys Res Commun. 2018;496: 450-454.

32. Han SJ, Jang HS, Kim JI, Lipschutz JH, Park KM. Unilateral nephrectomy elongates primary cilia in the remaining kidney via reactive oxygen species. Sci Rep. 2016;6:22281.

33. Lipschutz JH, Guo W, O'Brien LE, Nguyen YH, Novick P, Mostov $\mathrm{KE}$. Exocyst is involved in cystogenesis and tubulogenesis and acts by modulating synthesis and delivery of basolateral plasma membrane and secretory proteins. Mol Biol Cell. 2000;11:4259-4275.

34. Park KM, Fogelgren B, Zuo X, Kim J, Chung DC, Lipschutz JH. Exocyst Sec10 protects epithelial barrier integrity and enhances recovery following oxidative stress, by activation of the MAPK pathway. Am J Physiol Renal Physiol. 2010;298:F818-F826.

35. Yang G, Sun X, Wang R. Hydrogen sulfide-induced apoptosis of human aorta smooth muscle cells via the activation of mitogen-activated protein kinases and caspase-3. FASEB J. 2004;18:1782-1784.

36. Liu D, Wang Z, Zhan J, Zhang Q, Wang J, Zhang Q, Xian X, Luan Q, Hao A. Hydrogen sulfide promotes proliferation and neuronal differentiation of neural stem cells and protects hypoxia-induced decrease in hippocampal neurogenesis. Pharmacol Biochem Behav. 2014;116:55-63.

37. Choi DE, Jeong JY, Choi H, Chang YK, Ahn MS, Ham YR, Na KR, Lee KW. ERK phosphorylation plays an important role in the protection afforded by hypothermia against renal ischemia-reperfusion injury. Surgery. 2017;161:444-452. 